\title{
Decomposição da Produtividade para o setor de Bens de Capital: a contribuição dos serviços intermediários para o crescimento da produtividade
}

\author{
Wallace Marcelino Pereira ${ }^{\dagger}$ \\ Adilson Giovanni ${ }^{\ddagger}$ \\ Resumo \\ Kleverton Clovis de Oliveira Saath ${ }^{\S}$
}

Kaldor apresentou quatro leis que evidenciam a importância do setor industrial e do setor externo para o crescimento econômico. Contudo, a importância do setor de serviços não é considerada nas leis desenvolvidas. Este artigo questiona se estas leis não são válidas também para o setor de serviços, defendendo a importância dos serviços intermediários para o crescimento da produção. A decomposição da Produtividade Total dos Fatores (PTF), segundo a metodologia proposta por Bauer (1990) e Kumbhakar (2000) é utilizada para verificar se o setor de serviços contribuiu para o crescimento da produção do setor de bens de capital no período 1995-2009. Os resultados obtidos corroboram a hipótese de que o desenvolvimento do setor de serviços intermediário contribui para o crescimento da quantidade produzida pelo setor de bens de capital. A segunda lei proposta por Kaldor pode ser complementada: o crescimento da produtividade industrial depende do crescimento da produção industrial, mas o crescimento industrial depende do surgimento de uma relação de crescente simbiose entre serviços intermediários e indústria.

\section{Palavras Chave: Serviços; Leis de Kaldor; Bens de Capital}

\begin{abstract}
Kaldor presented four laws that highlight the importance of the industrial sector and the external sector for economic growth. However, the importance of the service sector is not considered in the developed laws. This article questions whether these laws are also valid for the service sector, defending the importance of intermediary services for the growth of production. The total factor productivity (TFP) decomposition according to the methodology proposed by Bauer (1990) and Kumbhakar (2000) is used to verify if the services sector contributed to the production growth of the capital goods sector in the period 1995- 2009. The results obtained corroborate the hypothesis that the development of the intermediary services sector contributes to the growth of the quantity produced by the capital goods sector. The second law proposed by Kaldor can be complemented: the growth of industrial productivity depends on the growth of the industrial production, but the industrial growth depends on the emergence of a relation of growing symbiosis between intermediate services and industry.
\end{abstract}

Key words: services; Kaldor laws; Capital goods

\subsection{Crescimento, produtividade e competitividade}

\author{
JEL: L6 L8 O4
}

\footnotetext{
${ }^{\dagger}$ Doutorando em Economia do CEDEPLAR/UFMG.

¥ Doutorando em Economia do CSE/UFSC.

$\S$ Mestre em Economia pelo CSE/UFSC.
} 


\section{INTRODUÇÃO}

O artigo seminal que aponta a importância da indústria, de autoria de Nicolas Kaldor, intitulado "Causes of the Slow Rate of Economic Growth of the United Kingdom" de 1966, constitui referência sobre a importância do setor industrial para o desenvolvimento econômico. Sinteticamente, Lamonica e Feijó (2010) resumem as proposições de Kaldor em quatro leis, a saber: i) existe relação positiva entre o crescimento da indústria e o crescimento do produto agregado, daí quanto maior a taxa de crescimento da indústria, maior será a taxa de crescimento do produto nacional; ii) há relação positiva entre a taxa de crescimento da produtividade na indústria e o crescimento do produto industrial, sendo a relação de causalidade na direção de quanto maior a taxa de crescimento da indústria, maior será também a taxa de crescimento da produtividade; iii) quanto maior a taxa de crescimento das exportações, maior será o crescimento do produto, dado que este gera condições para alcançar o mercado externo, e; iv) o crescimento da economia no longo prazo não é restringido pela oferta, mas sim pela demanda, assim a principal restrição da demanda ao crescimento do produto numa economia aberta é o balanço de pagamentos, na medida em que este reflete a composição setorial da economia e as elasticidades renda da demanda por exportações.

Nestes termos, a primeira lei mostra ser a indústria o "motor do crescimento" dado constituir o setor mais dinâmico e difusor de inovações. A segunda lei é a lei de Kaldor-Verdoon em que se estabelece uma relação de causalidade entre taxa de crescimento de produtividade e a taxa de crescimento da produção (LAMONICA; FEIJÓ, 2010). Nesse caso, uma elevação da demanda induz o aumento da produção que leva necessariamente ao aumento da produtividade, mas cabe ressaltar que tal situação ocorre somente em setores com economias de escala dinâmica. Nesses termos, trata-se da concepção kaldoriana da indústria como locus do processo inovativo com extensão para os demais setores. A terceira lei aproxima-se do modelo export-led growth, no sentido de que o crescimento da economia é liderado pelas exportações, como componente autônomo da demanda (GUIMARÃES 2002; LAMONICA; FEIJÓ, 2010). Por fim, pela quarta lei ou lei de Thirlwall se têm que o crescimento liderado pela demanda é limitado pela condição de equilíbrio do balanço de pagamentos, dada as elasticidades renda do comércio exterior e da composição setorial da economia. Ou seja, a restrição do balanço de pagamentos se encontra na composição setorial e na magnitude das elasticidades renda da demanda do comércio exterior (MISSIO, F. J.; JAYME JR., F. G. ; CONCEICAO, O. A, 2014).

As leis acima consideradas olham apenas para o setor industrial e para a balança de pagamentos. Desconsideram a contribuição do setor de serviços intermediários para o crescimento econômico e para o desenvolvimento. Este artigo defende que a segunda lei proposta por Kaldor, apesar de ser válida, precisa ser relativizada. $\mathrm{O}$ crescimento do setor industrial realmente contribui para o crescimento da produtividade industrial, no entanto a literatura de serviços intermediários mostra que este setor também contribui para o crescimento da produção e da produtividade industrial. Assim, o crescimento da produção industrial não depende apenas do crescimento da produção total deste setor, mas também da presença de serviços intermediários adequados.

Para testar a hipótese levantada no parágrafo anterior realiza-se a revisão da literatura sobre o tema. Posteriormente, o modelo de fronteira estocástica, desenvolvido por Aigner Lovell e Schimidt (1967); Meeusen et al. (1977) e Battese et al. (1977) é utilizado para mensurar a contribuição do setor de serviços para o crescimento da produção do setor de bens de capital. A transversalidade do setor de bens de capital justifica a escolha deste setor para se verificar a contribuição do setor de serviços para o comportamento apresentado pela produtividade no período 1995-2009. As estimações são realizadas para uma amostra multi-país, para o período 1995-2009. Dado que os países que compõem a amostra são heterogêneos, possuindo estruturas produtivas e tecnológicas diferentes, se torna difícil extrair conclusões empiricamente mais robustas, bem como interpretá-las analiticamente. Isto potencializa os resultados extraídos, dado que a metodologia de fronteira estocástica permite visualizar as causas desta heterogeneidade.

Além desta introdução, este artigo possui sete seções. A seção 2 apresenta a revisão histórica da literatura sobre o setor de serviços intermediários; a seção 3 realiza uma contextualização do setor de serviços intermediários; a seção 4 justifica a escolha do setor de bens de capital; a seção 5 apresenta a 
metodologia utilizada para realizar a decomposição da produtividade, e os dados utilizados; em seguida, a seção 6 apresenta os resultados encontrados; por fim, a seção 7 realiza algumas considerações finais.

\section{EVOLUÇÃO DO DEBATE TEÓRICO SOBRE O SETOR DE SERVIÇOS}

A construção do corpo teórico e o debate sobre o setor de serviços tem sua origem no período entre guerras e pode ser entendido por meio de uma periodização do seguinte tipo (OLIVEIRA, 2011): 1) do inicio do século XX até o final da década de 1950;2) Estudos da década de 60; 3) os avanços da década de 70-80, e por fim; 4) estudos a partir da década de 90. O período que compreende o início do século XX até o final da década de 50 é marcado pelos estudos iniciais sobre o setor de serviços. Neste período era atribuída pouca importância a este setor, e ele era considerado elemento residual da economia. Apenas em meados do século XX ele começa a ser considerado em uma tipologia econômica mais definida. Fisher (1933) dividiu a economia em três setores, a saber: setor primário (agrícola), setor secundário (indústria) e setor terciário. Este último congregava tudo que não se encontrava nos dois primeiros setores. Clark (1940) define com mais clareza o setor terciário como serviços, e avança em sua análise de mudança das estruturas econômicas. Segundo o autor, nos países onde a divisão social do trabalho é mais profunda, o setor de serviços é maior e apresenta renda per capita mais elevada.

$\mathrm{Na}$ década de 60, os estudos sobre serviços passam a focar mais a demanda intermediária, e os preços relativos. Nesse período criticam-se as abordagens teóricas desenvolvidas por Fisher e Clark. As novas evidências encontradas indicam que a Teoria dos estágios de desenvolvimento não pode ser observada quando testada contra a produtividade dos serviços, e o ritmo fraco da economia americana (OLIVEIRA, 2011). Nesse sentido, segundo Katouzian (1970), apud por OLIVEIRA (2011, pg. 35) são basicamente três as criticas, a saber: (i) A elasticidade renda da demanda: os testes estatísticos realizados indicaram que a elasticidade renda da demanda por serviços nos EUA não foi significativamente maior que 1 (um) no período 1923-1963 (FUCHS, 1965). Em outros termos, as alterações dos gastos das famílias não se deveram, necessariamente, a variações da renda; (ii) As vantagens comparativas entre os países no contexto dos anos 60: que passam a ser discutidas nos termos das abordagens sobre subdesenvolvimento (baseado em KUZNETS, 1959 apud KATOUZIAN, 1970). As evidências encontradas pelos estudos econométricos não corroboraram a hipótese de que as economias com maior participação dos serviços possuem produto per capita mais alto. O que necessariamente invalida a hipótese de que este setor é um indicador de desenvolvimento; (iii) $\mathrm{O}$ aumento ou o declínio nas participações dos setores tende a ser explicado pelas diferenças na taxa de crescimento ou hiato de produtividade: este é um resultado direto da crítica à ideia de que o setor de serviços possui elasticidade renda da demanda maior que 1. Assim, surge uma nova abordagem baseada nas diferenças de produtividade, que procura mostrar que o crescimento dos serviços é determinado pela demanda intermediária por serviços como resultado da reestruturação produtiva (FUCHS, 1965).

Baumol (1967) procura entender o setor de serviços e sua relação com o setor industrial. As afirmações realizadas pelo autor ficaram conhecidas na literatura especializada em serviços pelo termo "doença dos custos". Este advoga que o crescimento do setor de serviços implica em redução da produtividade da economia, devido à substituição do setor dinâmico (indústria) pelo setor menos dinâmico (serviços). Os serviços possuem menor nível de produtividade, contudo os salários desse setor acompanham os salários dos demais setores levando ao aumento dos custos de produção nos serviços. Gershumy (1973) discorda da análise realizada por Baumol (1967), os salários dos serviços finais não conseguem manter taxas de crescimento elevadas, sendo necessário mudar o foco da análise para os serviços intermediários.

A partir da década de 70 e 80 os países avançados entram em processo de crescimento relativo dos serviços em suas economias. Nesse período discutem-se as consequências da emergência do paradigma da Tecnologia da Informação e Comunicação (TIC) e de atividades de P\&D no setor de serviços. A teoria neoclássica não conseguia explicar o crescimento dos serviços e a forma de classificação das atividades de serviços para efeitos de estudo e análise da contribuição do setor. Nesse contexto, Summers (1985) investigou a relação existente entre a participação dos serviços nos gastos e os níveis de renda em vários países. Segundo o autor, os gastos com serviços aumentaram mais que proporcionalmente ao aumento da 
renda nominal, apesar da participação dos serviços nos gastos reais serem constantes entre os países que possuem níveis de renda variados. Adicionalmente, Roach (1988) mostrou que, a partir da década de 80, a taxa de crescimento do estoque de capital vinha apresentando taxas maiores no setor de serviços do que na indústria para os Estados Unidos, principalmente em TIC.

No que se refere à teoria neoclássica Griliches $(1979 ; 1984)$ tentaram identificar no setor de serviços a mesma relação, entre $P \& D$ e crescimento econômico, existente no setor industrial, cujo resultado considerou-se inexistente. Nesse período o "paradoxo de Solow" passa a ser o maior problema para explicar a razão pela qual os EUA, mesmo com grande investimento em TIC, não conseguia ampliar sua produtividade, cujas taxas de crescimento vinham se reduzindo desde o inicio da década de 70 .

Quanto à questão do debate sobre a classificação do setor de serviços, pode-se citar Katouzian (1970) e sua classificação baseada nos níveis de desenvolvimento de um país e na evolução da estrutura econômica. Segundo o referido autor, os serviços apresentam três subdivisões, a saber: 1) serviços novos e, portanto, sensíveis à variação da renda; 2) serviços complementares, e que estão relacionados com a indústria de transformação e o processo de industrialização, e; 3) serviços antigos que estão relacionados com o processo de industrialização e urbanização, mas que perdem relevância com o tempo e são substituídos por novos tipos de serviços. Além desta classificação, Browning e Singelman (1978) apresentam uma classificação mais ampla, a qual discrimina os serviços entre serviços intermediários e serviços finais. Segundo estes autores a classificação dos serviços deve combinar a função econômica, o tipo de usuário e a orientação de mercado.

Os estudos, a partir da década de 90, se deparam com a reversão das taxas de crescimento da economia americana, e a consolidação dos serviços como essenciais ao processo de globalização no que se refere à redução dos custos de transporte, infraestrutura energética e difusão de tecnologias da informação e telecomunicações, e pelas críticas à abordagem de Baumol. A literatura de serviços começou a utilizar uma abordagem neochumpeteriana e evolucionária para explicar a contribuição do setor para o crescimento econômico (OLIVEIRA, 2011). Neste período, a crescente utilização de serviços no processo produtivo levou Shih (1992) a desenvolver a "Curva Sorridente", segundo a qual as atividades de serviços associados ao processo produtivo agregam mais valor ao bem final do que a produção em si (Figura 01).

Conforme enfatizado por Gereffi e Frederick (2010) e Zhan e Schimanski (2014), os países em desenvolvimento participam das cadeias globais de valores através da realização de atividades intensivas em trabalho e realizando atividades de fabricação. Os países que possuem maior participação na Cadeia Global de Valor produzem bens com maior participação dos serviços (eles migraram para as pontas da "Curva Sorridente"), principalmente serviços de design, desenvolvimento da marca e Marketing. Portanto, o que diferencia os países desenvolvidos dos países em desenvolvimento, no comércio internacional, é a especialização dos primeiros em serviços ${ }^{* *}$.

\section{Figura 01 - Curva Sorridente}

\footnotetext{
** TEMPEST (1996), HESSELDAHL (2010), LINDEN ET AL. (2007, 2009), ALI-YRKKO ET AL. (2010), REIS (2014), SOUSA (2009), CAMPOS E CALANDRO (2008)], HOBDAY (1995), GEREFFI (1999), CRUZ-MOREIRA E FLEURY (2003), GEREFFI E MEMEDOVIC (2003) e HUMPHREY (2004).
} 


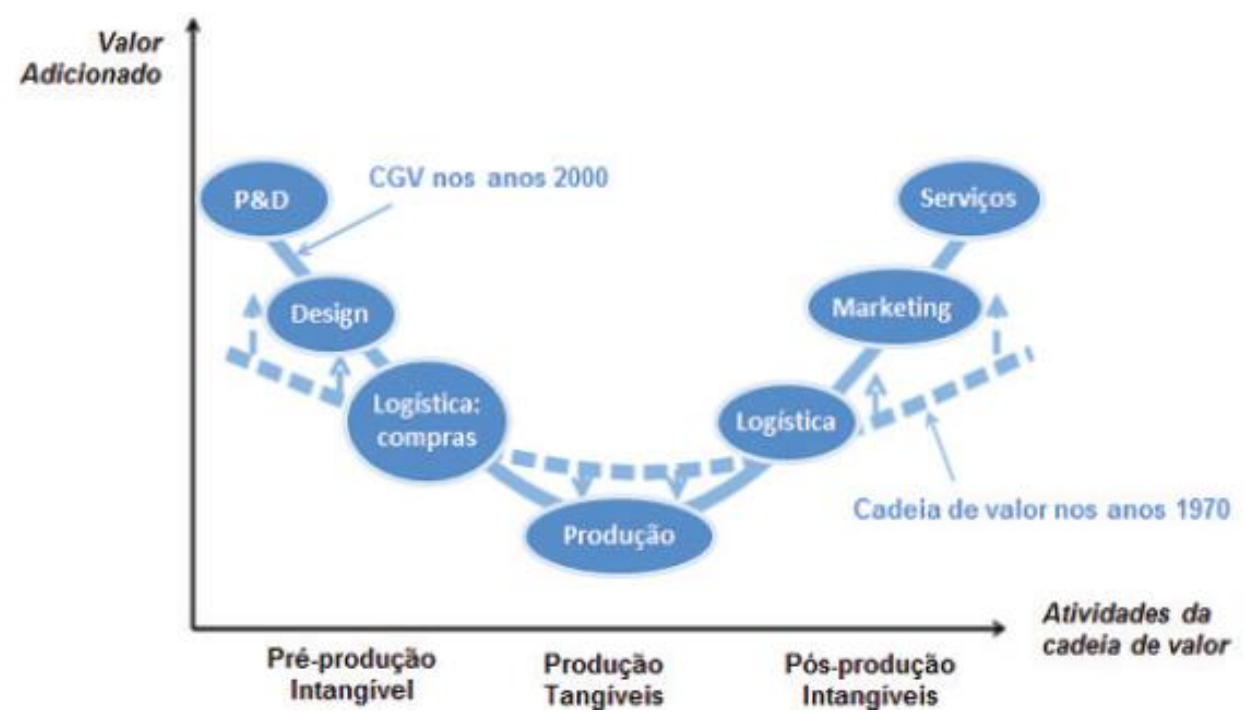

Fonte: OCDE/ OMC (2013, p. 216).

Diante do aumento da complexidade no processamento de dados, criação de softwares e aplicativos e ampliação da dinâmica de comunicação, Pavitt e Bell (1993), criaram o termo "intensivo em informação" que compreende todos os serviços vinculados a atividades financeiras, varejo, publicações, e telecomunicações. A crescente interatividade entre consumidor e prestador de serviço levou autores como Buzzacchi et al. (1995) a indicar a necessidade de se estudar as diferentes formas de disponibilização dos serviços, que vão da integração das cadeias de suprimentos à serviços integrados de logística, principalmente no que tange às atividades ligadas aos Serviços Intensivos em Conhecimento - SIC que passaram a se destacar no fim do século passado.

Posteriormente, Oulton (2001) questionou a hipótese de "Doenças de Custos", defendida por Baumoll (1967). Apropriando-se da classificação dos serviços, proposta por Browning e Singelman (1978), o autor argumenta que a "doença de custos" ocorre somente se o crescimento da produtividade na indústria implicar em aumento da participação dos serviços finais no valor adicionado. Segundo Oulton (2001), o aumento da participação dos serviços no valor adicionado não ocorre por meio do crescimento da participação dos serviços finais. O que se verifica, é a diminuição da participação destes serviços, e o aumento da participação dos serviços intermediários. Dado que estes serviços são utilizados como insumos pela indústria, pequenas taxas de crescimento na sua produtividade são suficientes para que a produtividade da economia como um todo aumente. Nestes termos, o aumento da participação dos serviços não leva à estagnação econômica.

Paralelo a isto, a literatura de serviços intensivos em conhecimento (KIBS) mostra que estes suprem a indústria com o conhecimento necessário à realização de inovações. Estes conhecimentos emergem da interação existente entre serviços e indústria e não de atividades específicas encontradas em um destes setores. Assim, esta literatura apresenta evidências de que os serviços intermediários contribuem para a geração de inovações no setor industrial, sendo que em muitos casos as inovações industrial só ocorrem na presença destes serviços (MILES et Al., 1994, 1995, 2008; HERTOG, 2000; MULLER, 2001; CZARNITZKI e SPIELKAMP, 2000; MIOZZO, SOETE, 2001).

As evidências mais recentes são ainda mais poderosas. Elas mostram que os serviços de negócios também estão sujeitos às leis de Kaldor. Estes serviços também apresentam ganhos de escala e, também são capazes de geram um processo de crescimento autossustentado (DI MEGLIO et al., 2015; DASGUPTA e SINGH, 2007).

Outra linha de estudo, que se encontra em ascensão, analisa a participação dos serviços na indústria, cabendo destacar a contribuição de Castellacci (2008). No Brasil, esta linha de pesquisa é representada por autores como Arbache (2014) e Arbache e Aragão (2014). Estes procuram entender como a dinâmica do setor de serviços, principalmente dos serviços intermediários, tem influenciado na dinâmica da economia e da indústria de transformação brasileira. 
Castellacci (2008) dividiu as atividades em quatro grupos: Fornecedores de conhecimento avançado: possuem capacidade tecnológica elevada e são provedores de conhecimento para outros setores, sendo discriminadas em: 1) firmas industriais especializadas em máquinas e equipamentos de precisão; e 2) firmas de serviços especializadas em soluções técnicas e conhecimentos tecnológicos como $\mathrm{P} \& \mathrm{D}$, software, engenharia e consultoria. Fabricação de produtos em Massa: fabricam bens industriais finais e intermediários e que possuem elevada capacidade de desenvolvimento de produtos e processos internamente e através de cooperação externa. Serviços de Infraestrutura de apoio: produzem bens e serviços intermediários. A inovação ocorre através da aquisição de máquinas, equipamentos e diversas formas de conhecimento tecnológico. Bens e Serviços Pessoais: possuem baixo conteúdo tecnológico e limitada capacidade de desenvolvimento de novos produtos e processos. A inovação ocorre através da aquisição de máquinas, equipamentos e serviços de outros setores.

Apesar de todas as evidências encontradas na literatura especializada em serviços, não se encontrou nenhum estudo que buscasse identificar se o setor de serviços contribui para o aumento da produtividade do setor de bens de capital. O próprio Castellacci colocou o setor de bens de capital na mesma categoria que algumas atividades de serviços, mas não mostrou o modo como estes se complementam. Este estudo explora mais detalhadamente esta relação, identificando se o setor de serviços intermediários contribui para o crescimento da produtividade do setor de bens de capital. Caso isto seja confirmado se terá evidências favoráveis à revisão da segunda lei de Kaldor, não é o crescimento do setor industrial que resulta em crescimento da produtividade industrial, mas o surgimento de uma relação de maior simbiose entre serviços e indústria.

\section{CONTRIBUIÇÃO DOS SERVIÇOS INTERMEDIÁRIOS}

Conforme mostrado na seção anterior, os serviços estão assumindo importância crescente na explicação da dinâmica econômica, a literatura que estuda a relação existente entre serviços e indústria se encontra em franca expansão. Duas tendências explicam o aumento da inter-relação existente entre serviços e indústria: 1) o aumento da participação das atividades de serviços; e, 2) o processo de terceirização de serviços ligados às empresas, tais como pesquisa, desenvolvimento, financiamento e logística (CZARNITZKI E SPIELKAMP, 2000). A análise para os países que participam da OCDE revela que a participação dos serviços aumentou em todos os setores industriais, com exceção de refino de petróleo. Outra característica associada ao setor de serviços foi o aumento da participação das indústrias intensivas em serviços na produção industrial (LESHER e NORDÅS, 2006).

Como resultado, a discriminação dos bens finais vendidos aos consumidores em serviços e indústria é cada vez mais inadequada, proporção crescente dos produtos é vendida em "pacotes" que incorporam produção física e serviços de forma simbiótica. Esta afirmação é válida, principalmente, para os produtos tecnologicamente mais avançados, que possuem maior quantidade de serviços incorporados no seu valor final (ARBACHE, 2015). Nesse sentido, os serviços intermediários podem ser divididos em dois grupos, a saber: 1) serviços de valor; e, 2) serviços de custo. Os serviços de valor se referem às atividades que agregam valor à produção, resultando no aumento do preço de mercado, da produtividade e do retorno do capital. Por sua vez, os serviços de custo contribuem para a competitividade das empresas, pois aumentam a eficiência da produção, mas não resultam em diferenciação do produto, ou em aumento do valor de venda dos mesmos (ARBACHE, 2014).

A importância dos serviços de custo e dos serviços de valor varia de produto para produto, e depende da interação existente entre serviços e indústria (PILAT E WÖLFL, 2004). Os serviços de custos são mais importantes para garantir a competitividade dos setores industriais que fabricam produtos commoditizados, que são mais homogêneos entre si. Os serviços de valor, por sua vez, são mais importantes em mercados que possuem grau mais elevado de sofisticação, nos quais é possível se realizar a diferenciação dos produtos (MOREIRA, 2015). Neste sentido, a adição de serviços de valor ao processo produtivo pode ser explicada pela possibilidade de se realizar discriminação de preço de $3^{\circ}$ grau. Em outros termos, a existência de um mercado composto por diferentes grupos de consumidores, pode levar as 
empresas a tentar fabricar produtos com diferentes características, buscando extrair parte do excedente do consumidor. A adição de serviços ao bem final pode aumentar a qualidade associada pelos consumidores. Estes se dispõem a pagar preço mais elevado, o que viabiliza a discriminação de preço. Se o custo incorrido pela empresa com a adição de serviços for inferior à quantidade de excedente do consumidor extraída a discriminação de preço se mostra vantajosa (PINDYCK e RUBINFELD, 2006, p. 331).

A literatura de serviços mostra que as atividades intensivas em serviços de valor estão concentradas nos países desenvolvidos, enquanto que a fabricação e os serviços de custo são encontrados em países em desenvolvimento (UNCTAD, 2013). A concentração dos serviços de valor nos países desenvolvidos é explicada pela maior oferta de capital humano e de capacidades produtivas destes países. As empresas mais avançadas tecnologicamente se localizam nestes países, existindo maior demanda por serviços intermediários. Por outro lado, os países em desenvolvimento caracterizam-se pela maior presença de serviços de custos, em detrimento dos serviços de valor (UNESCO, 2015). Além disso, a participação dos serviços como insumo intermediário da indústria varia entre os países. As atividades industriais são mais dependentes do setor de serviços como fornecedor de insumos intermediários do que as demais atividades econômicas (ACEMOGLU et al., 2007). Esta afirmação é especialmente verdadeira para os setores mais intensivos em tecnologia, como é o caso do setor de computadores e produtos para escritório (NORDÅS, 2008).

Assim, a participação crescente dos serviços, como insumo intermediário da indústria significa que a produtividade apresentada pelos serviços exerce influência cada vez mais elevada sobre a produtividade industrial. Deste modo, serviços pouco produtivos e de baixa qualidade implicam em bens finais mais caros e de pior qualidade ${ }^{\dagger \dagger}$. De modo semelhante, Lesher e Nordås (2006) mostram que a participação dos serviços de negócios nos insumos intermediários, utilizados pela indústria, possui correlação positiva com a relação valor/peso dos produtos exportados. Com base neste resultado, os autores argumentam que a maior participação dos serviços de negócios como insumo intermediário. resulta em maior capacidade de agregação de valor à produção final. A maior participação dos serviços está associada à produção de produtos com maior qualidade.

\section{POR QUE O SETOR DE BENS DE CAPITAL?}

A escolha do setor de bens de capital para a análise da contribuição do setor de serviços intermediários se justifica pelas características apresentadas por este setor. Ele é transversal aos demais setores industriais, que dependem, em menor ou maior grau, do seu comportamento. Este setor é responsável por suprir os demais setores com os meios de produção necessários. Logo, os ganhos de produtividade e as inovações observadas no setor de bens de capital se difundem para os demais setores (MARSON, 2008).

Segundo Rosenberg (1963), todas as inovações que resultam em inovação de produto ou de processo produtivo requerem ajustamentos no setor de bens de capital. As empresas deste setor têm se tornado altamente especializadas, em resposta às especificações técnicas requeridas pelos demais setores industriais. Nesses termos, destaca-se o caráter multidimensional da inovação neste setor, ele é foco dos processos de progresso técnico que impulsionam a inovação e a produtividade dos demais setores produtivos. Contudo, o setor de bens de capital também tem o seu processo de aprendizado fomentado pelos demais setores, uma vez que estes também incorrem em processos de inovação e progresso técnico.

O setor de Bens de Capital foi profundamente afetado pelo surgimento e expansão da microeletrônica digital. Ele verificou a ampliação do conteúdo eletrônico e de software embarcados em todos os seus segmentos, principalmente com o novo desdobramento do paradigma tecnológico microeletrônico, caracterizado pela conectividade e pela "internet das coisas" (ALEM; PESSOA, 2005). Os elementos apontados nos parágrafos anteriores fazem com que este setor possua dependência elevada do setor de serviços intermediários, o qual deve exercer contribuição elevada para a produção e a competitividade do setor de bens de capital.

\footnotetext{
${ }^{+\dagger}$ Berlingieri (2013); Amiti e Wei (2005); Francois e Woerz (2008); Carter (1970) e Barker e Forssell,(1992).
} 


\section{MÉTODO}

A produtividade total dos fatores (PTF) é obtida com o uso do método de fronteira estocástica de produção, proposto por Aigner, Leobel e Schmidt (1977) e Meusen e Broeck (1977). Este método foi aprimorado e utilizado, posteriormente, por Pitt e Lee (1981), Schimidt e Sickles (1984) e Battese e Coeli (1995). A fronteira de produção é estimada de duas formas funcionais alternativas: o modelo Cobb-Douglas e o modelo Translog. O teste de adequação indicou que o modelo Translog deve ser utilizado para a estimação da função de produção, dada por:

$$
\begin{aligned}
& \ln Y_{i t}=\alpha_{1}+\alpha_{2} t+\alpha_{3} \frac{1}{2} t^{2}+\alpha_{4} \ln K_{i t}+\alpha_{5} \ln L_{i t}+\sum_{l=1}^{5} \alpha_{5+l} \ln I_{l, i t}+\alpha_{11} t \ln K_{i t}+\alpha_{12} t \ln L_{i t}+\sum_{l=1}^{5} \alpha_{12+l} t \ln I_{l, i t}+ \\
& \alpha_{18} \frac{1}{2} \ln K_{i t}{ }^{2}+\alpha_{19} \frac{1}{2} \ln L_{i t}{ }^{2}+\sum_{l=1}^{5} \frac{1}{2} \alpha_{19+l} t \ln I_{l, i t}{ }^{2}+\alpha_{25} \ln K_{i t} L_{i t}+\sum_{l=1}^{5} \alpha_{25+l} K \ln I_{l, i t}+ \\
& +\sum_{l=1}^{5} \alpha_{31+l} L \ln I_{l, i t}+\sum_{l=2}^{5} \alpha_{35+l} I_{2, i t} \ln I_{l, i t}+\sum_{l=3}^{5} \alpha_{39+l} I_{3, i t} \ln I_{l, i t}+\sum_{l=4}^{5} \alpha_{42+l} I_{1, i t} \operatorname{lnI}_{l, i t}+\alpha_{45} I_{4, i t} \ln I_{5, i t}+v_{i t}-u_{i t}, \\
& \text { sendo: }
\end{aligned}
$$

$\mathrm{Y}_{\mathrm{it}}=$ Valor adicionado do país $i$ no período $t$ para setor de Bens de Capital, em milhões;

$\mathrm{K}_{\mathrm{it}}=$ Estoque de capital físico do país $i$ no período $t$ para o setor de Bens de Capital, em mil milhões;

$L_{i t}=$ Número de horas trabalhadas no país $i$ no período $t$ no setor de Bens de Capital;

$\mathrm{I}_{1, \mathrm{it}}=$ Insumos Intermediários oriundos da indústria e da agropecuária, utilizados pelo país $i$ no período $t$ pelo setor de Bens de Capital, em milhões (o Apêndice A2 discrimina as atividades que compõe cada setor considerado);

$\mathrm{I}_{2, \mathrm{t}}=$ Insumos Intermediários oriundos de atividades de serviços de valor, em milhões;

$\mathrm{I}_{3, \mathrm{it}}=$ Insumos Intermediários oriundos de atividades de serviços de custo, em milhões;

$\mathrm{I}_{4, \mathrm{it}}=$ Insumos Intermediários oriundos de atividades de serviços de Correios e Telecomunicações, em milhões;

$\mathrm{I}_{5, \mathrm{it}}=$ Insumos Intermediários oriundos de Outras atividades de serviços, em milhões;

$\alpha_{i}=$ Constante;

$v_{i t}=$ Distúrbios aleatórios da função de produção que por hipótese segue uma distribuição normal com media zero e variância constante, e

$-u i t=$ Ineficiência técnica de produção, modelado da seguinte forma:

sendo:

$$
u_{i t}=\delta z_{i t}+\omega_{i t}
$$

$z_{i t}=\left(z_{1 t}, z_{2 t}, z_{3 t}, z_{4 t}, z_{5 t}, z_{6 t}\right)$, um vetor composto por variáveis que explicam a ineficiência técnica,

sendo $\delta$ um parâmetro associado a $z_{i t}$;

$\omega_{i t}=$ um termo de erro, que possui distribuição normal por hipótese $N\left(0, \sigma_{\omega}^{2}\right)$;

$u_{i t}$ é independentemente distribuído, seguindo distribuição normal truncada com média zero;

$\omega_{i t}=\delta z_{i t}$ e variância constante $\sigma_{\omega}^{2}$.

As variáveis utilizadas para modelar o termo de ineficiência técnica são escolhidas com base em diversos trabalhos empíricos que mostram a influência que estas variáveis exercem sobre a eficiência produtiva, sendo apresentadas a seguir:

$z_{1 t}=$ Constante.

$z_{2 t}=$ Efeito tendência.

$z_{3 t}=$ Taxa de câmbio. Segundo Bresser-Pereira (2012) a apreciação do câmbio influencia no crescimento da produção, e na concorrência entre produtores locais e estrangeiros;

$z_{4 t}=$ Logaritmo do consumo do governo, em milhões. Maior gasto do governo está associado à maior ineficiência técnica;

$z_{5 t}=$ Inflação, a instabilidade dos preços exerce uma influência positiva sobre a ineficiência;

$z_{6 t}=$ Desvio da inflação em relação à inflação dos Estados Unidos;

$z_{7 t}=$ Instituições, Pilar 1 do Global Competitiveness Report (DEMSETZ, 1967, ACEMOGLU $1999 \mathrm{e}$ SCARPETTA, 2002).

$z_{8 t}=$ Infraestrutura, Pilar 2 do Global Competitiveness Report (FELIPE, 2001).

$z_{9 t}=$ Ambiente Macroeconômico, Pilar 3 do Global Competitiveness Report.

$z_{10 t}=$ Saúde e educação primária, Pilar 4 do Global Competitiveness Report. 
$z_{11 t}=$ Educação elevada e treinamento, Pilar 5 do Global Competitiveness Report .

$z_{12 t}=$ Eficiência do mercado de bens, Pilar 6 do Global Competitiveness Report.

$z_{13 t}=$ Eficiência do mercado de trabalho, Pilar 7 do Global Competitiveness Report (SCARPETTA, 2002 e NICKELL e LAYARD, 1999).

$z_{14 t}=$ Desenvolvimento do mercado financeiro, Pilar 8 do Global Competitiveness Report (BERGER, et al, 1993 e BERGER, et al, 1997).

$z_{15 t}=$ Tamanho do mercado, Pilar 10 do Global Competitiveness Report (MELITZ, 2008)

$z_{16 t}=$ Sofisticação dos negócios, Pilar 11 do Global Competitiveness Report (PORTER, 2009).

$z_{17 t}=$ Inovação, Pilar 12 do Global Competitiveness Report. (GRILICHES, 1998).

$z_{18 t}=$ Índice de capital humano (BARRO, 1993).

$z_{19 t}=$ Sofisticação das exportações.

\subsection{Testes}

O ajuste do modelo foi verificado através da aplicação de cinco testes ${ }^{\S \S}$. O teste de máxima verossimilhança verifica qual a forma funcional que melhor se ajusta à função de produção estimada. O segundo teste identifica se houve progresso técnico no setor de bens de capital no período 1995-2009. O terceiro teste mostra se a ineficiência técnica exerceu influência significativa, em termos estatísticos, sobre a produtividade do setor. O quarto teste verifica se os indicadores sofisticação das exportações, eficiência do mercado de bens e nível de desenvolvimento do mercado financeiro devem ser deixados no modelo (2), dado que eles não são significativos em termos estatísticos. O último teste mostra se os indicadores saúde e educação primária, educação elevada e treinamento; e, Índice de Capital Humano - IDH devem ser deixados no modelo estimado, mesmo não sendo significativos.

\subsection{Dados utilizados}

A Tabela 01 apresenta os dados utilizados para realizar as estimações supracitadas. Todos os insumos intermediários considerados foram deflacionados pelo indicador de inflação dos insumos intermediários, disponibilizado por World Input Output Database (TIMMER, 2015). O ano de 1995 foi definido como ano-base.

\section{Tabela 1 - Discriminação dos indicadores utilizados}

\begin{tabular}{lll}
\hline Sigla & Indicador & Fonte \\
\hline VA & Valor adicionado bruto do setor de bens de & World Input Output \\
K & $\begin{array}{l}\text { Espital, a preços de 1995 } \\
\text { capital } \\
\text { Total de horas trabalhadas no setor de bens de } \\
\text { capital }\end{array}$ & World Input Output \\
L & $\begin{array}{l}\text { Quantidade de insumos oriundos da indústria e da } \\
\text { agropecuária* }\end{array}$ & World Input Output \\
Indústria e & $\begin{array}{l}\text { Agregação de atividades específicas de serviços } \\
\text { Agropecuária }\end{array}$ & World Input Output \\
Valor & $\begin{array}{l}\text { Agregação de atividades específicas de serviços } \\
\text { relacionadas à serviços de custo* }\end{array}$ & World Input Output \\
Custo & $\begin{array}{l}\text { Demais atividades de serviços* } \\
\text { Quantidade de insumos utilizados pela indústria }\end{array}$ & World Input Output \\
Outros & World Input Output \\
Telecomunicações & Co bens de capital oriundos da atividade de & \\
& $\begin{array}{l}\text { Nível de preços do valor adicionado bruto } \\
\text { Inflação subtraída da inflação dos Estados Unidos }\end{array}$ & Pen World Table \\
Desvio da inflação & World Table \\
\hline
\end{tabular}

\# A presença de multicolineariedade entre os indicadores inviabilizou a adição do Pilar 9 do Global Competitiveness Report

$\S \S$ Para mais detalher ver Feitosa (2009) e Bettese et al., (1995). 


\begin{tabular}{|c|c|c|}
\hline Consumo do governo & $\begin{array}{l}\text { Quantidade consumida pelo governo, em } \\
\text { percentual do PIB }\end{array}$ & Pen World Table \\
\hline Taxa de câmbio & $\begin{array}{l}\text { Taxa de câmbio relativa, base: taxa de câmbio dos } \\
\text { Estados Unidos em } 1995\end{array}$ & Pen World Table \\
\hline $\begin{array}{l}\text { Sofisticação das } \\
\text { exportações }\end{array}$ & Nível de sofisticação dos bens exportados & Pen World Table \\
\hline Instituições & $1^{\circ}$ Pilar do Global Competitivenes report & Web Forun \\
\hline Infraestrutura & $2^{\circ}$ Pilar do Global Competitivenes report & Web Forun \\
\hline $\begin{array}{l}\text { Ambiente } \\
\text { macroeconômico }\end{array}$ & $3^{\circ}$ Pilar do Global Competitivenes report & Web Forun \\
\hline $\begin{array}{l}\text { Saúde e educação } \\
\text { primária }\end{array}$ & $4^{\circ}$ Pilar do Global Competitivenes report & Web Forun \\
\hline $\begin{array}{l}\text { Educação elevada e } \\
\text { treinamento }\end{array}$ & $5^{\circ}$ Pilar do Global Competitivenes report & Web Forun \\
\hline $\begin{array}{l}\text { Eficiência no mercado } \\
\text { de bens }\end{array}$ & $7^{\circ}$ Pilar do Global Competitivenes report & Web Forun \\
\hline $\begin{array}{l}\text { Desenvolvimento do } \\
\text { mercado financeiro }\end{array}$ & $8^{\circ}$ Pilar do Global Competitivenes report & Web Forun \\
\hline Tamanho do mercado & $10^{\circ}$ Pilar do Global Competitivenes report & Web Forun \\
\hline $\begin{array}{l}\text { Sofisticação dos } \\
\text { negócios }\end{array}$ & $11^{\circ}$ Pilar do Global Competitivenes report & Web Forun \\
\hline Inovação & $12^{\circ}$ Pilar do Global Competitivenes report & Web Forun \\
\hline $\begin{array}{l}\text { Índice de capital } \\
\text { humano }\end{array}$ & Indicador criado por Barro e Lee (1993) & Pen World Table \\
\hline
\end{tabular}

Fonte: Elaboração própria, *Utilizados como insumos intermediários pelo setor de bens de capital

Os dados oriundos do World Competitiviness Report se referem apenas ao período 2008-2009. Como as variáveis que compõem esta base de dados são indicadores institucionais, que não se alteram no curto prazo, se justifica a extrapolação dos valores observados neste ano para todo o período 1995-2009. Argumentação semelhante é válida para o índice de sofisticação das exportações, cujos valores para os anos de 1995, 1996, 2008 e 2009 foram obtidos por extrapolação do dado existente para o ano mais próximo.

Ademais, é preciso enfatizar algumas limitações adicionais apresentadas pela base de dados utilizada. Os dados de competitividade, fornecidos pelo World Competitiviness Report, não são construídos a partir de critérios objetivos. Eles dependem de informações qualitativas e subjetivas, o que dificulta a realização de inferências gerais. Infelizmente, não se encontrou nenhuma base de dados institucionais alternativa, mais confiável, que disponibilizasse dados para o conjunto de países utilizados e para o período considerado. Assim, optou-se por utilizar os dados disponibilizados pelo World Competitiviness Report, apesar das limitações apresentadas por esta base.

\section{RESULTADOS OBTIDOS}

A análise dos resultados se encontra dividida em duas partes, a saber: a primeira parte caracteriza o setor de bens de capital e apresenta os resultados encontrados para os testes citados, e; na segunda parte são apresentados os resultados obtidos para as regressões estimadas.

\subsection{Caracterização}

A análise da participação do setor de serviços como fornecedor de insumos intermediários para o setor de bens de capital evidencia que apenas $0,017 \%$ dos insumos adquiridos por este setor são oriundos da atividade de Telecomunicações e Correios. Entre os países com maior participação deste setor, como fornecedor de insumos intermediários, destacam-se a Austrália, 0,0435\%, Letônia, 0,032\% e Malta, $0,028 \%$. A Alemanha aparece na $10^{\mathrm{a}}$ posição, $0,02 \%$, os EUA na $13^{\mathrm{a}}$ posição, $0,017 \%$, e o Japão na $25^{\mathrm{a}}$ posição, 0,01\%. Coreia do Sul, Eslovênia e México são os países com menor participação, 0,005\%, 0,007\% e $0,007 \%$, respectivamente.

Os serviços de custos representam, em média, apenas 0,018\% dos insumos intermediários utilizados pelo setor de bens de capital. Holanda, França, Suíça e Alemanha são os países com maior participação, 
0,040\%, 0,034\%, 0,027\% e 0,025\%. Os Estados Unidos aparecem na $7^{\mathrm{a}}$ posição, 0,022\%, e o Japão na $23^{\mathrm{a}}$ posição, com $0,013 \%$. Os países com menor participação são Rússia, Turquia e República Tcheca, 0,005\%, $0,009 \%$ e $0,010 \%$, respectivamente.

A participação dos serviços de custos na demanda de insumos intermediários do setor de bens de capital é ainda inferior à participação dos demais serviços. O país que possui maior participação média é a Holanda, com 0,0005\%, seguida pela Dinamarca, 0,0005\% e pela Polônia, 0,0004\%. Por outro lado, Coreia do Sul, Chipre e Brasil são os países com menor participação, 0,0001\%, 0,0002\% e 0,0002\%, respectivamente.

O setor Indústria e Agropecuária é o que apresenta maior participação como fornecedor de insumos intermediários para o setor de bens de capital no período analisado. Coreia do Sul, Eslovênia e Turquia são os países com maior participação, 99,983\%, 99,982\% e 99,981\%, respectivamente. Por outro lado, Austrália, Holanda e Suécia são os países com menor participação, 99,930\%, 99,93\% e 99,94\%.

Os resultados apresentados nos parágrafos anteriores revelam uma característica marcante da indústria de bens de capital, a quantidade de serviços utilizados no processo produtivo é muito pequena. Conforme já enfatizado, esta baixa participação dos serviços como insumo não inviabiliza a realização das regressões propostas. Pelo contrário, os serviços exercem influência qualitativa sobre a produção de bens finais, apesar de serem utilizados em pequenas quantidades, eles podem influenciar no valor adicionado pelo setor.

A análise da taxa média anual de crescimento do setor de serviços como insumo intermediário utilizado pelo setor de bens de capital no período $1995-2009^{* * *}$, indica que os serviços de valor observaram a maior taxa de crescimento, $6 \%$, seguidos pelos serviços de custo, 4,2\%, Outros serviços 3,7\% e Correios e Telecomunicações, 3,2\%. Para Correios e Telecomunicações, a República Tcheca, Malta, Estônia e Polônia foram os países que apresentaram maiores taxas médias anuais de crescimento, 130\%, 63\%, 12\% e 11\%, respectivamente. A Turquia, Estados Unidos e Japão, apresentaram retração na participação deste setor como fornecedor de insumos intermediários, $-8 \%,-4 \%$ e $-1 \%$ e a Alemanha apresentou crescimento de apenas $0,5 \%$.

Em serviços de valor, República Tcheca, Malta e Estônia foram os países que apresentaram maiores taxas de crescimento deste setor como fornecedor de insumos intermediários para o setor de bens de capital, $148 \%, 26 \%$ e $21 \%$, respectivamente. Turquia, Estados Unidos e Brasil apresentaram retração, $-8 \%,-1 \%$ e $-1 \%$, respectivamente. O Japão apresentou crescimento de apenas $-0,1 \%$ e a Alemanha ficou na $24^{a}$ posição, 4\%. República Tcheca, Malta e Estônia também foram os países com maior taxa anual média de crescimento dos serviços de custos, $60 \%, 15 \%$ e $12 \%$, respectivamente. Turquia, Estados Unidos, Japão, Brasil, Grécia e Rússia apresentaram recuo da participação, em $-9 \%,-3 \%,-2 \%,-2 \%,-1 \%$, e $-1 \%$, respectivamente. Ademais, a Alemanha ficou na $24^{\text {a }}$ posição com crescimento de $3 \%$.

O setor Indústria e Agropecuária cresceu, em média, 4\% ao ano no período 1995-2009. Os países com maior crescimento foram República Tcheca, 44\%, Eslováquia, 15\% e Estônia, 13\%. Por outro lado, Turquia, Malta, Estados Unidos, Brasil, Japão e Grécia observaram recuo no uso de insumos intermediários oriundos deste setor, $14 \%, 6 \%, 3 \%, 2 \%, 2 \%$ e $1 \%$, respectivamente. Os testes realizados (Apêndice A1) indicam que o modelo deve ser estimado com a forma funcional Translog, que o setor apresentou progresso técnico e eficiência técnica. Ademais, as variáveis $\mathrm{z}_{12 \mathrm{t}}, \mathrm{z}_{14 \mathrm{t}}$ e $\mathrm{z}_{20 \mathrm{t}}$ e $\mathrm{z}_{10 \mathrm{t}}, \mathrm{z}_{11 \mathrm{t}}$ e $\mathrm{z}_{18 \mathrm{t}}$ devem ser mantidas no modelo estimado.

\subsection{Modelo estimado}

Conforme sugerido por Marinho et al., (2000), o modelo (1) é estimado com efeitos fixos. Definida a forma funcional adequada para a estimação da fronteira de produção, vide Figura 1, e realiza a estimação da mesma através da equação (1). Posteriormente, se estima a ineficiência técnica, equação (2) ${ }^{\dagger \dagger \dagger}$. A Tabela 2 apresenta os valores obtidos para os coeficientes estimados.

\section{Tabela 2 - Valor obtido para os coeficientes estimados}

\footnotetext{
${ }^{* * *}$ Exceto República Tcheca e Malta que representam outliers.

††' O software FRONTIER 4.1 foi utilizado para estimar a fronteira de produção e a ineficiência técnica.
} 


\begin{tabular}{|c|c|c|c|c|c|}
\hline Variável & Coef. $^{\#}$ & E.P. & Variável & Coef. & E.P. \\
\hline cons & $124,991 *$ & 22,375 & t*Telecomunicação & 0,003 & 0,009 \\
\hline$t$ & $-0,573^{*}$ & 0,150 & Capital*Trabalho & $-0,139 *$ & 0,019 \\
\hline$t^{\wedge} \mathbf{2}$ & 0,000 & 0,002 & Capital*Indústria e agropecuária & $-0,178^{*}$ & 0,052 \\
\hline $\boldsymbol{K}$ & $3,095^{*}$ & 0,576 & Capital*Valor & $-0,024$ & 0,043 \\
\hline$L$ & $-1,308$ & 0,897 & Capital*Custo & $0,275^{*}$ & 0,047 \\
\hline Indústria e agropecuária & $-21,320^{*}$ & 3,817 & k outros & $-0,083^{*}$ & 0,031 \\
\hline Serviços de valor & $7,899 *$ & 2,167 & Capital*Telecomunicação & $-0,058$ & 0,037 \\
\hline Serviços de custo & $13,657^{*}$ & 3,345 & Trabalho*indústria e agropecuária & $0,164 *$ & 0,082 \\
\hline Outros serviços & $-4,483 *$ & 1,575 & Trabalho*Valor & 0,079 & 0,088 \\
\hline $\begin{array}{l}\text { Serviços de } \\
\text { telecomunicações }\end{array}$ & $3,484^{*}$ & 1,907 & Trabalho*Custo & $-0,017$ & 0,082 \\
\hline$K^{\wedge} 2$ & $0,161^{*}$ & 0,019 & Trabalho*Outros & 0,069 & 0,055 \\
\hline$L^{\wedge} 2$ & $0,077^{*}$ & 0,045 & Trabalho*Telecomunicações & $-0,195^{*}$ & 0,077 \\
\hline $\begin{array}{l}\text { Indústria e } \\
\text { agropecuária^2 }\end{array}$ & $1,881^{*}$ & 0,334 & Indústria e Agropecuária*Valor & $-0,724 *$ & 0,202 \\
\hline Valor ${ }^{\wedge} 2$ & $1,052 *$ & 0,244 & Indústria e Agropecuária*Custo & $-1,390^{*}$ & 0,272 \\
\hline Custo^2 $^{\wedge}$ & $0,540 *$ & 0,314 & Indústria e Agropecuária*Outros & $0,370^{*}$ & 0,129 \\
\hline Outros`2 $^{\wedge}$ & $-0,169^{*}$ & 0,101 & $\begin{array}{l}\text { Indústria e } \\
\text { Agropecuária*Telecomunicações }\end{array}$ & $-0,143$ & 0,164 \\
\hline Telecomunicações^2 & $-0,398^{*}$ & 0,164 & Valor*Custo & $0,527 *$ & 0,209 \\
\hline t.Capital & $-0,013^{*}$ & 0,002 & Valor*Outros & $-0,512 *$ & 0,110 \\
\hline t.trabalho & $0,012 *$ & 0,004 & Valor*Telecomunicações & $-0,288^{*}$ & 0,149 \\
\hline t*indústria e agropecuária & $0,058^{*}$ & 0,013 & Custo*Outros & $-0,275^{*}$ & 0,147 \\
\hline t*Valor & $-0,036^{*}$ & 0,010 & Custo*Telecomunicações & $0,257 *$ & 0,157 \\
\hline t*Custo & $-0,028^{*}$ & 0,012 & Outros*Telecomunicações & $0,691 *$ & 0,094 \\
\hline t*Outros & 0,007 & 0,007 & & & \\
\hline$\sigma_{u}$ & 0,013 & & & & \\
\hline$\sigma_{v}$ & 0,05 & & & & \\
\hline$\gamma$ & 0,22 & & & & \\
\hline
\end{tabular}

Fonte: Elaboração própria, Coef. são os coeficientes estimados e E.P. é o erro padrão, * Significativo ao nível de confiança de $95 \%$.

O coeficiente estimado para a variável $t$ é significativo ao nível de confiança de $95 \%$. Todavia, este coeficiente apresenta sinal negativo, indicando uma tendência negativa para a produção de bens de capital no período em análise. O coeficiente estimado para o capital também é significativo para um nível de confiança de $90 \%$. Ele mostra que o aumento em $1 \%$ na quantidade empregada de capital resulta em aumento mais do que proporcional da produção, 3,095\%. Este resultado confirma a importância do capital para este setor, evidenciando a tendência de acumulação de capital no setor.

O coeficiente estimado para o fator trabalho não é significativo ao nível de confiança de $90 \%$. Isto indica que a quantidade utilizada de trabalho não exerce influência elevada sobre a quantidade produzida pelo setor de bens de capital. Dado que o setor apresenta ganhos de escala, coeficiente elevado associado à capital e coeficiente não significativo para trabalho, é possível se aumentar a produção no setor substituindo-se trabalhadores por capital.

Os insumos intermediários, oriundos do setor Indústria e agropecuária, apresentam coeficiente significativo ao nível de confiança de $95 \%$. Todavia, o sinal encontrado para este fator de produção é negativo, indicando que o aumento em $1 \%$ na quantidade utilizada resulta em queda de $21,32 \%$ na quantidade produzida. Este resultado contraria as expectativas a priori. Uma interpretação inicial leva à conclusão de que é possível se aumentar a produção diminuindo-se a quantidade utilizada de insumos intermediários oriundos do setor indústria e agropecuária, o que não faz sentido.

Esta interpretação mostra-se inadequada. Para compreender por que este coeficiente apresenta sinal negativo é preciso realizar uma rápida contextualização do modo como a Microeletrônica está 
alterando as relações de produção no setor de bens de capital. O advento da Microeletrônica significa que este setor está demandando cada vez mais insumos oriundos do setor de serviços e que a propagação da Microeletrônica está resultando na substituição dos insumos oriundos da indústria e da agropecuária por insumos oriundos do setor de serviços intermediários (MELO, 1998). O resultado encontrado para o coeficiente estimado para o setor Indústria e agropecuária está apenas evidenciando os efeitos do advento da microeletrônica sobre o setor de bens de capital, aqui representados pelo aumento da produção, ao mesmo tempo em que se observa diminuição da quantidade de insumos oriundos da indústria e da agropecuária.

Conforme enfatizado por Alem e Pessoa (2005), a microeletrônica exerce influência elevada sobre a produtividade apresentada pelo setor de Bens de capital, induzindo a obtenção de progresso técnico. Todavia, o desenvolvimento da microeletrônica está demandando o surgimento de serviços especializados (MELO, 1998). O que, por sua vez, resulta em maior importância do setor de serviços como fornecedor de insumos intermediários. Ademais, ressalta-se que o setor de microeletrônica está alterando o modo como os insumos interagem com o processo produtivo. Estes insumos não entram apenas como fatores de produção utilizados no processo produtivo, eles interagem com o processo produtivo em si, alterando o modo como as transações são realizadas e como os bens são produzidos, o que resulta em aumento da produtividade (BRYNJOLFSSON, 2000).

A fronteira de produção estimada para o setor de bens de capital evidencia a importância que os serviços intermediários possuem para este setor. Todos os coeficientes, estimados para as atividades de serviços são significativos ao nível de confiança de 90\%. Ademais, o sinal encontrado para todas as atividades é positivo, exceto Outros serviços. Isto indica que os serviços intermediários exercem influência positiva sobre a quantidade produzida pelo setor de bens de capital. De forma mais específica, a variação em $1 \%$ na quantidade utilizada de serviços de valor implica em variação de $7,899 \%$ na quantidade produzida; a variação em $1 \%$ na quantidade utilizada de serviços de custo resulta em variação de $13,657 \%$ na produção; e, a variação em $1 \%$ na quantidade utilizada de serviços de Telecomunicação e Correios resulta em variação de 3,484\% na quantidade produzida pelo setor de bens de capital.

Por outro lado, a variação de $1 \%$ na quantidade utilizada de Outros serviços resulta em variação de $-4,483 \%$ na quantidade produzida pelo setor. O sinal negativo encontrado para este indicador já era esperado, pois ele é constituído por um conjunto de atividades de serviços que não contribuem diretamente para o processo produtivo e que não entram no chão de fábrica, sendo apenas necessárias para a manutenção das atividades das empresas. A maior utilização destes serviços não implica em aumento da produção, apenas em aumento dos custos incorridos.

Os parâmetros estimados para os fatores elevados ao quadrado não evidência alteração do sinal dos coeficientes. A única exceção é Correios e Telecomunicação, cujo sinal é negativo. Porém, o coeficiente estimado é baixo, de modo que este fator possui contribuição líquida positiva. Isto é, o maior uso de novas tecnologias resulta em maior produção.

De modo geral, os resultados revelam a importância crescente do setor de serviços intermediários (MELO, 1998) e das novas tecnologias de comunicação para o aumento na produção do setor de bens de capital. A maior utilização de insumos oriundos do setor de serviços não resulta apenas em maior produção, mas em bens com maior qualidade, o que se reflete em maior valor adicionado (LESHER e NORDÅS, 2006 e SHIH, 1992). Logo, a participação do setor de serviços como fornecedor de insumos para o setor de bens de capital se coloca como diferencial competitivo para os países que o utilizam com maior intensidade. Os valores elevados encontrados para os coeficientes estimados, apenas confirmam esta afirmação, pequenos aumentos na quantidade utilizada de insumos intermediários oriundos do setor de serviços resultam em aumento considerável na qualidade do bem produzido, o que se traduz em maior agregação de valor.

Estes resultados estão em sintonia com as novas evidências encontradas pela literatura KIBS, a qual mostra que os serviços intermediários fornecem conhecimentos para o setor industrial, contribuindo para o desenvolvimento de inovações de produto e, principalmente, de processo. Assim, a adição mesmo que de pequenas quantidades de serviços ao setor industrial pode contribuir para o crescimento da produção deste setor, dada a natureza possuída por estes serviços. Estes não entram como insumos tradicionais, mas 
atuam sobre o processo de produção como um todo, o modificando de modo a se tornar mais eficiente e produtivo.

Os coeficientes estimados para o produto cruzado da tendência contra os fatores de produção são todos significativos ao nível de confiança de $95 \%$. O sinal encontrado é positivo para todos os coeficientes, exceto Outros serviços e Telecomunicações. Este resultado mostra que o aumento na quantidade utilizada destes insumos contribuiu para o aumento na produção do setor.

Os resultados obtidos para as variáveis compostas pelos produtos cruzados dos fatores de produção apresentam sinal negativo para a maioria dos coeficientes, indicando a presença de deseconomias de escopo. Os únicos fatores que apresentam coeficiente significativo e sinal positivo são capital e serviços de custos; trabalho e serviços e agropecuária; trabalho e serviços de valor; trabalho e outros; e, Indústria e Agropecuária e Outros, o que indica a presença de economias de escopo na utilização destes fatores.

Diferentes variáveis influenciam no nível de eficiência dos países, explicando por que os países se encontram abaixo da fronteira de produção. A figura 1 retrata essa problemática, o país A se encontra na fronteira eficiente de produção, aloca os fatores de produção de forma eficiente, o que possibilita a máxima produção com a tecnologia disponível. Por outro lado, o país B se encontra abaixo da fronteira eficiente de produção, não alocando os fatores de produção de forma eficiente. A pergunta que surge é: Por que este país não se encontra na fronteira eficiente de Produção?

Produção

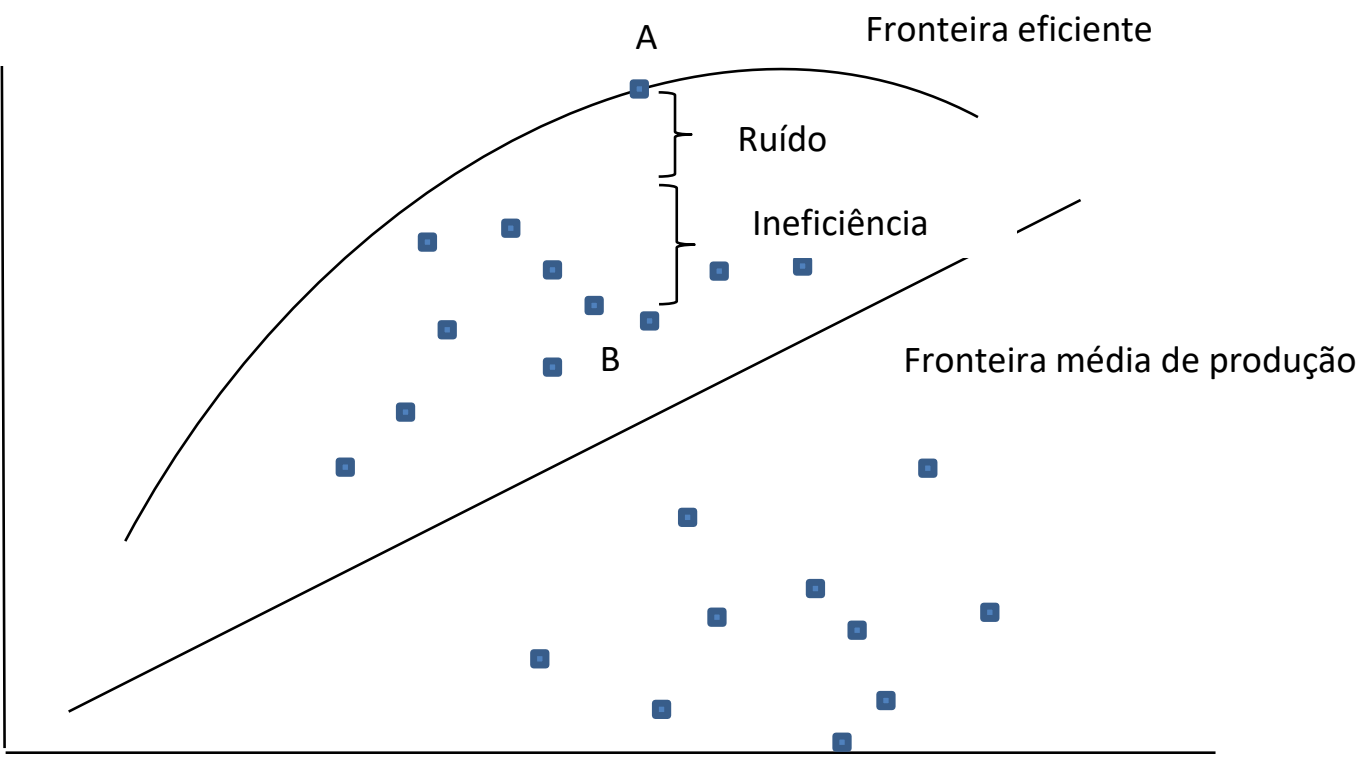

Fonte: Os autores

Figura 1: Fronteira de produção

Fator de produção

O modelo 2 busca responder esta pergunta, para isto retrata a contribuição das variáveis que determinam a ineficiência do setor de bens de capital. Todas as variáveis utilizadas para modelar a ineficiência, citadas na metodologia, são significativas ao nível de confiança de $90 \%$. As únicas exceções são: a Saúde e educação primária; a Educação Elevada e treinamento; a Eficiência do mercado de bens; o Desenvolvimento do mercado financeiro e o Índice de Capital Humano.

Tabela 3. Modelagem da Ineficiência

\begin{tabular}{lrrlrr}
\hline Variável & Coef. & E.P. & Variável & Coef. & E.P. \\
\hline $\boldsymbol{c}$ & $-9,99 *$ & 4,26 & Saúde e educação primária & $-0,54$ & 0,65 \\
$\boldsymbol{t}$ & $0,00^{*}$ & 0,00 & Educação Elevada e treinamento & $-0,45$ & 0,38 \\
Inflação & $-0,45^{*}$ & 0,15 & Eficiência do mercado de bens & $-0,71$ & 0,44 \\
Desvio da inflação & $0,00^{*}$ & 0,00 & Eficiência do mercado de trabalho & $0,50 *$ & 0,19 \\
Consumo do governo & $0,15 *$ & 0,05 & Desenvolvimento do mercado financeiro & 0,10 & 0,28 \\
Câmbio & $0,02 *$ & 0,01 & Tamanho do mercado & $0,31 *$ & 0,09 \\
Sofisticação das & & & Sofisticação dos negócios & \\
exportações & $0,30^{*}$ & 0,14 & & $0,60 *$ \\
Instituições & $0,88^{*}$ & 0,30 & Inovação & 0,34 \\
\hline
\end{tabular}




\begin{tabular}{|c|c|c|c|c|}
\hline Infraestrutura & $-0,19 *$ & 0,11 Índice de capital Humano & 0,23 & 0,18 \\
\hline Ambiente macroeconômico & $0,93 *$ & 0,15 & & \\
\hline
\end{tabular}

Coef. são os coeficientes estimados e E.P. é o erro padrão

* Significativo ao nível de confiança de $95 \%$.

Incialmente a variável $t$, tendência, apresenta relação positiva e significativa com a ineficiência técnica, mas seu coeficiente é próximo de zero. Isto é, a ineficiência permanece constante ao longo do tempo, de modo que os países de fronteira eficiente permanecem nessa condição, enquanto que os países que estão abaixo da fronteira eficiente não conseguem modificar a sua situação.

A taxa de inflação também explica por que alguns países se encontram mais distantes da fronteira eficiente do que outros. O sinal encontrado para esta variável é negativo, indicando que maiores taxas de inflação resultam em maior eficiência. Isto é, os países que apresentam taxas mais elevadas de inflação se encontram mais próximos da fronteira técnica do que os demais. Uma possível explicação para isto é a existência de poder do mercado neste setor, o que faz com que as empresas consigam repassar preços com maior facilidade. Outros resultados importantes mostrados pelo modelo de ineficiência técnica é que as variáveis infraestrutura e inovação possuem uma relação estatisticamente significativa e estão positivamente relacionadas com a eficiência dos países. O que mostra que estas variáveis são determinantes e influenciam na capacidade dos países em migrar para a fronteira eficiente.

Por outro lado, a variável desvio da inflação americana, proxy para estabilidade dos países, mostra que o setor de bens de capital possui maior ineficiência técnica em países que apresentam menor estabilidade econômica. Análise semelhante é válida para a variável Consumo do governo. Este resultado mostra que países que gastam mais apresentam menor eficiência técnica, sendo também encontrado em Feitosa (2009).

A taxa de câmbio também apresenta sinal positivo, mostrando que desvalorizações cambiais aumentam a ineficiência. Este sinal está diferente do esperado, contrariando a análise realizada por BresserPereira (2012), sendo a crescente globalização uma possível explicação para isto. Os países utilizam cada vez mais insumos importados, desvalorizações cambiais aumentam o preço destes insumos, estimulando o uso de insumos nacionais de qualidade inferior, o que faz o país se distanciar da fronteira eficiente.

Ademais, as variáveis: sofisticação das exportações; Instituições; Ambiente macroeconômico; eficiência do mercado de trabalho; e, sofisticação dos negócios estão com sinal diferente do esperado. Estudos futuros são necessários para identificar por que estas variáveis apresentam estes sinais. Este trabalho também abre espaço para que a metodologia de decomposição da fronteira estocástica - pela parte determinística da função (FEITOSA, 2009) -, em eficiência técnica, sofisticação das exportações, eficiência alocativa, ganhos de escala e progresso técnico seja analisada para cada país, identificando quais foram os principais fatores que determinaram o crescimento da PTF em cada país. Esta metodologia possibilita identificar os países com maior crescimento da produtividade total dos fatores e quais destes fatores explicam este crescimento.

\section{CONSIDERAÇÕES FINAIS}

A contribuição do setor de serviços para o desenvolvimento econômico e para a competitividade do setor industrial foi, por muitos anos, negligenciada pela literatura econômica. Este artigo apresenta as diferentes formas através das quais o setor de serviços contribui para a produtividade e a competitividade dos países. Três argumentos diferentes são apresentados: 1) a utilização de insumos oriundos do setor de serviços implica em mudança qualitativa nas características assumidas pelo bem produzido. A maior utilização de serviços intermediários resulta em bens com qualidade mais elevada e maior valor agregado, os quais podem ser vendidos por valores mais elevados para os consumidores finais. Logo, os países que possuem setor de serviços mais desenvolvido possuem maior participação na cadeia global de valor (SHIH, 1992) de modo que a maior utilização de serviços está associada a discriminação de preços de $3^{\circ}$ grau, o que permite a extração de parte do excedente do consumidor (PINDYCK \& RUBINFELD, 2006, p. 331) e 3) os produtos tecnologicamente mais sofisticados utilizam uma quantidade maior de serviços intermediários na sua produção, principalmente serviços relacionados à inovação. 
Estes três argumentos convergem no mesmo sentido: os países que possuem setor de serviços intermediários mais desenvolvido produzem bens com qualidade mais elevada; vendidos com maior valor agregado; eles também inovam mais e produzem bens tecnologicamente mais sofisticados. Como consequência, o setor de serviços é um vetor central na determinação do grau de competitividade apresentado pelos países. Os países que possuem setor de serviços mais desenvolvido possuem maior competitividade. Por outro lado, os países que possuem setor de serviços menos desenvolvido são menos competitivos, apresentando menor nível de produtividade e menor renda per capta.

A regressão estimada para o setor de Bens de Capital confirmou a hipótese levantada. Os setores de serviços considerados, apesar de apresentarem baixa participação no total de insumos intermediários utilizados, contribuíram para a adição de valor à produção final. $\mathrm{O}$ valor elevado encontrado para os coeficientes estimados esta de acordo com a "Curva Sorridente", pequenas variações na quantidade utilizada de serviços resultam em variações consideráveis na quantidade produzida pelo setor de bens de capital.

Estes resultados corroboram a hipótese levantada, indicando que o setor de serviços intermediários contribui para o aumento da produção do setor de bens de capital. Isto possibilita argumentar que a segunda lei da Kaldor está correta, mas talvez careça de complementação: o crescimento da produção industrial resulta em crescimento da produtividade deste setor, contudo, o setor de serviços intermediários também contribui para o crescimento da produção do setor de bens de capital. O crescimento da produtividade industrial depende do surgimento de uma relação de crescente simbiose entre serviços e indústria e não apenas do crescimento do setor industrial. Ademais, a modelagem da ineficiência revelou que a inflação, a inovação e a infraestrutura dos países contribuem positivamente para a redução da ineficiência técnica.

\section{REFERÊNCIAS}

ACEMOGLU, D.; AGHION, P.; LELARGE, C.; VAN REENEN, J.; ZILIBOTTI, F. Technology, information, and the decentralization of the firm. The Quartely Journal of Economics. v. 122, n. 4, p. 1759-1799, 2007.

ACEMOGLU, Daron; ZILBOTTI, Fabrizio. Productivity differences. National Bureau of Economic Research, 1999.

AIGNER, D. J.; LOVELL, C. A. K. SCHMIDT, P. Formulation and estimation of stochastic frontier production functions models. Journal of Econometrics, v.6, p. 21-37, 1977.

ALI-YRKKÖ, J.; ROUVINEN, P.; SEPPÄLÄ, T.; YLÄ-ANTTILA, P. Who captures value in global supply chains? Case Nokia N95 Smart Phone. [S.1.], 2010. (ETLA Discussion Paper, n. 1240).

AMITI, Mary; WEI, Shang-Jin. Fear of service outsourcing: is it justified? Economic policy, v. 20, n. 42, p. $308-347,2005$.

ARBACHE, J. Produtividade nos serviços. In: Produtividade no Brasil desempenho e determinantes, Volume 2, IPEA, 2015.

ARBACHE, Jorge. Dinâmica recente da conta de transações correntes e a conta de serviços. Available at SSRN 2443043, 2014.

BARKER, Terry; FORSSELL, Osmo. Manufacturing, Services and Structural Change, 1979-1984. In: Structural change in the UK economy. Cambridge University Press Cambridge, 1992.

BARRO, Robert J.; LEE, Jong-Wha. International comparisons of educational attainment. Journal of monetary economics, v. 32, n. 3, p. 363-394, 1993.

BATTESE, George Edward; COELLI, Tim J. A model for technical inefficiency effects in a stochastic frontier production function for panel data. Empirical economics, v. 20, n. 2, p. 325-332, 1995.

Baumol, W. J. "Macroeconomics of Unbalanced Growth: The Anatomy of Urban Crises." American Economic Review, 57, no. 3 (June): 415-26, 1967.

BERGER, Allen N.; HUMPHREY, David B. Efficiency of financial institutions: International survey and directions for future research. European journal of operational research, v. 98, n. 2, p. 175-212, 1997. 
BERGER, Allen N.; HUNTER, William C.; TIMME, Stephen G. The efficiency of financial institutions: a review and preview of research past, present and future. Journal of Banking \& Finance, v. 17, n. 2, p. 221-249, 1993.

BERLINGIERI, G. Essays on international trade and firm organization. 2013. Tese (PhD) Department of Economics of the London School of Economics. Londres, dez. 2013.

BRYNJOLFSSON, Erik; HITT, Lorin M. Beyond computation: Information technology, organizational transformation and business performance. The Journal of Economic Perspectives, p. 23-48, 2000.

CAMPOS, S. H.; CALANDRO, M. L. Nova confi guração do mercado de tra-balho internacional de calçados e os impactos sobrea indústria calçadista gaúcha. IV Encontro de Economia Gaúcha - EEG, PortoAlegre, 2008. Disponível em: <http://www.pucrs.br/eventos/eeg/trabalhos/estudos-setoriais-sessao13.doc>. Acesso em: 12.1.2016.

CARTER, Anne P. Structural change in the american economy. 1970.

CRUZ-MOREIRA, J.; Fleury, A. Cadeias de produção de roupas em Honduras e no Brasil: uma comparação em termos do progresso industrial. XXIV Congresso Internacional da Associação de Estudos Latino-Americanos. Disponível em: <http://lasa.international.pitt.edu/Lasa2003/CruzMoreiraJuanRicardo.pdf>. Acesso em: 10.01.2016.

CZARNITZKI, Dirk; RAMMER, Christian; SPIELKAMP, Alfred. Interaktion zwischen Wissenschaft und Wirtschaft in Deutschland: Ergebnisse einer Umfrage bei Hochschulen und öffentlichen Forschungseinrichtungen. ZEW-Dokumentation, 2000.

DASGUPTA, Sukti; SINGH, Ajit. Manufacturing, services and premature deindustrialization in developing countries: A Kaldorian analysis. In: Advancing Development. Palgrave Macmillan UK, 2007. p. 435-454.

DE BORJA REIS, Cristina Fróes; DE ALMEIDA, Julio Sérgio Gomes. A inserção do Brasil nas cadeias globais de valor comparativamente aos BRICS. 2014.

DEMSETZ, Harold. Toward a theory of property rights. The American economic review, p. 347-359, 1967.

DI MEGLIO, G. et al Services in Developing Economies: A New Chance for Catching-Up? 2015. SWPS 2015-32. Available at SSRN: https://ssrn.com/abstract=2744647 or http://dx.doi.org/10.2139/ssrn.2744647 FELIPE, Jesus. Aggregate production functions and the measurement of infrastructure productivity: a reassessment. Eastern Economic Journal, p. 323-344, 2001.

FEITOSA, Débora Gaspar. Três ensaios sobre crescimento econômico na América Latina e no Brasil. (Tese de Doutorado) - Universidade Federal do Ceará. 2009

FRANCOIS, J.; WOERZ, J. Producer services, manufacturing linkages, and trade. Journal of Industry, Competition and Trade. v. 8, n. 3-4, p 199-229. Out 2008.

GEREFFI, G. A commodity chains framework for analyzing global in-dustries. Disponível em: $<$ http://eco.ieu.edu.tr/wp-content/Gereffi_CommodityChains99.pdf $>$. Durham, 1999. Acesso em: 18.12.2015.

GEREFFI, Gary; FREDERICK, Stacey. The global apparel value chain, trade and the crisis: challenges and opportunities for developing countries. World Bank Policy Research Working Paper Series, 2010.

GRILICHES, Zvi. R\&D and productivity. National Bureau of Economic Research Books, 1998.

HESSELDAHL, A. The iPad: more than the sum of its parts. US\$270 More, Actually. Bloomberg Business Week, n. 24, 2010.

HERTOG, Pim D. Knowledge-intensive business services as co-producers of innovation. International Journal of Innovation Management, v. 4, n. 04, p. 491-528, 2000.

HOBDAY, M. East Asian latecomer firms: learning the technology of ele-tronics. World Development, v. 23, n. 7, p. 1.171-93. Elsevier, 1995.

HUMPHREY. J. Upgrading in global value chains. Working Paper 28, Inter-national Labor Organization, 2004. Disponível em: <http://www.ilo.int/wcmsp5/groups/public/---dgreports/--integration/documents/publication/wcms_079105.pdf>. Acesso em: 23.12.2015.

LESHER, Molly; NORDÅS, Hildegunn Kyvik. Business services, trade and costs. 2006.

LINDEN, G.; KRAEMER, K.; DEDRICK, J. Who captures value in a global innovation system? The case of Apple's iPod. Communications of the ACM, v. 52, n. 3, p. 140-144, 2009. 
MEEUSEN, Wim; VAN DEN BROECK, Julien. Efficiency estimation from Cobb-Douglas production functions with composed error. International economic review, p. 435-444, 1977.

MELITZ, Marc J.; OTTAVIANO, Gianmarco IP. Market size, trade, and productivity. The review of economic studies, v. 75, n. 1, p. 295-316, 2008.

MELO, Hildete Pereira de et al. O setor serviços no Brasil: uma visão global-1985/95. 1998.

MOREIRA, R. F. C. Descentralização da produção e produtividade no Brasil. Mar. 2015. $103 \mathrm{f}$. Dissertação (Mestrado em Economia) - Universidade de Brasília, Brasília, 2015.

MILES, I. et al. Knowledge Intensive Business Services: Their Roles as Users, Carriers and Sources of Innovation. PREST, Manchester, 1994.

MIOZZO, Marcela; SOETE, Luc. Internationalization of services: a technological perspective. Technological Forecasting and Social Change, v. 67, n. 2, p. 159-185, 2001.

MULLER E., ZENKER A. Business services as actors of knowledge transformation: the role of KIBS in regional and national innovation systems. Research Policy, v. 30, n. 9, p. 1501-16, 2001.

NICKELL, Stephen; LAYARD, Richard. Labor market institutions and economic performance. Handbook of labor economics, v. 3, p. 3029-3084, 1999.

Nordås, Hildegunn Kyvik. The Impact of Services Trade Liberalisation on Trade in Non-Agricultural Products. OECD Trade Policy Papers, 81, OECD Publishing, 2008.

OCDE/OMC. Interconnected economies: benefiting from global value chains. PreliminaryVersion. Genebra, 2013.

PILAT, Dirk; WÖLFL, Anita. ICT production and ICT use: what role in aggregate productivity growth?. The Economic impact of ICT-measurement, evidence, and implications. p. 85-104, 2004.

PITT, Mark M.; LEE, Lung-Fei. The measurement and sources of technical inefficiency in the Indonesian weaving industry. Journal of development economics, v. 9, n. 1, p. 43-64, 1981.

PORTER, Michael E.; SCHWAB, Klaus. The Global Competitiveness Report 2008-2009. In: World Economic Forum. 2009.

SCARPETTA, Stefano et al. The role of policy and institutions for productivity and firm dynamics: evidence from micro and industry data. 2002.

SHIH, S. Millenium transformation: change management for new Acer. Aspire Academy Series, [s.d.]. Disponível em: http://www.stanshares.com.tw/StanShares/upload/tbBook/1_20100817144639.pdf, acesso em: 01 dez. 2016.

SOUSA, A. C. Indústria calçadista brasileira e concorrência internacional: uma análise da qualidade dos produtos exportados e das estratégias ado-tadas pelas empresas (1989-2006). Dissertação (Mestrado em Economia), Faculdade de Ciências e Letras, Programa de Pós-Graduação em Econo-mia, Universidade Estadual Paulista, Araraquara, 2009.

TEMPEST, R. Barbie and the world economy. Los Angeles Times, 1996.

TIMMER, Marcel P. et al. An Illustrated User Guide to the World Input-Output Database: the Case of Global Automotive Production. Review of International Economics, 2015.

UNCTAD. World Investiment Report 2013 - Global value chains: investiment and trade for development. Nações Unidas. Nova Iorque e Genebra, 2013.

UNESCO. UNESCO Institute for Statistics (UIS). 2015. Disponível em: <http://www.uis.unesco.org/> . Acesso em 23 jan. 2016.

ZHANG, Liping; SCHIMANSKI, Silvana. Cadeias Globais de Valor e os Países em Desenvolvimento, Boletim de Economia e Política Internacional, 2014.

\section{APÊNDICE A1}

\section{APÊNDICE A1. TESTE REALIZADOS}

A Tabela 2 apresenta o valor encontrado para os testes realizados, conforme sugerido por Battese et al., (1995) e Feitosa (2009). 
Tabela 2 - Teste da razão de verossimilhança para os parâmetros estimados.

\begin{tabular}{|c|c|c|c|c|c|}
\hline Teste & $\begin{array}{l}\text { Hipótese } \\
\text { nula }\end{array}$ & $H_{0}$ & Valor de $\Lambda$ & $\begin{array}{l}\text { Valor } \\
\text { critico } \\
\end{array}$ & (nível de 5\%) \\
\hline \multicolumn{2}{|c|}{ Forma funcional } & $\alpha_{1}, \ldots, \alpha_{20}=0$ & $12.519,00$ & 66,16 & Rejeita-se $H_{0}$ \\
\hline \multicolumn{2}{|c|}{ Ausência de PT } & $\alpha_{2}, \alpha_{3}, \alpha_{8}, \alpha_{9}, \alpha_{10}, \alpha_{11}=0$ & 74,72 & 22,87 & Rejeita-se $H_{0}$ \\
\hline \multicolumn{2}{|c|}{$\begin{array}{l}\text { Inexistência inef. } \\
\text { Técnica }\end{array}$} & $z_{1 t}, z_{2 t}, \ldots, z_{8 t}=0$ & 697,77 & 37,93 & Rejeita-se $H_{0}$ \\
\hline \multicolumn{2}{|c|}{$\begin{array}{l}\text { Variáveis não } \\
\text { significativas }\end{array}$} & $z_{12 t}, z_{14 t}=0$ & 124,91 & 11,97 & Rejeita-se $H_{0}$ \\
\hline \multicolumn{2}{|c|}{ Qualificação } & $z_{10 t}, z_{11 t}, z_{18 t}=0$ & 45,45 & 11,97 & Rejeita-se $H_{0}$ \\
\hline
\end{tabular}

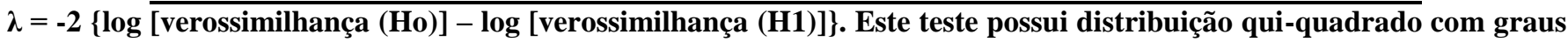
de liberdade equivalentes ao número de restrições independentes, ou seja, parâmetros testados iguais a 0.

O primeiro teste realizado verifica qual a forma funcional que deve ser utilizada para estimar a função de produção para o setor de bens de capital. Ele o modelo Translog, que admite retornos crescentes de escala, é a forma funcional que deve ser utilizada para realizar a estimação da função de produção, $K=12.519,00$. Dado nível de confiança de 95\%, o valor encontrado na tabela de Kodde \& Palm (1986) é igual a 66,16 com graus de liberdades iguais ao número de restrições.

O segundo teste, considera a hipótese nula de que o setor de bens de capital não apresentou progresso técnico no período 1995-2009. Esta hipótese é rejeitada ao nível de confiança de 95\%. O que evidencia a ocorrência de progresso técnico no setor. O terceiro teste realizado possui hipótese nula de inexistência de eficiência técnica. O resultado encontrado para $\Lambda, 697,77$ leva à rejeição da hipótese nula. Portanto, o setor possui ineficiência técnica, o que pode explicar a existência de diferenças significativas na produtividade entre os países. Este resultado indica que a sofisticação das exportações, a eficiência do mercado de bens e o nível de desenvolvimento do mercado financeiro contribuem para a explicação da ineficiência técnica observada no setor de bens de capital, entre os países, mesmo não sendo significativas.

Adicionalmente, testa-se se as variáveis $\mathrm{z}_{12 \mathrm{t}}, \mathrm{z}_{14 \mathrm{t}}$ e $\mathrm{z}_{20 \mathrm{t}}$ devem ser deixadas no modelo ou se a estimação deve ser realizada sem estas variáveis. Para isto, testa-se a hipótese nula de que o modelo sem estas variáveis é o que deve ser utilizado para modelar a ineficiência. O resultado encontrado para a razão de máximo verossimilhança, para o modelo sem as variáveis em questão, foi de 280,83, enquanto que a razão de máximo verossimilhança encontrada para o modelo com estas variáveis foi de 343,28. O que resultou em $\Lambda=124,91$, rejeitando-se a hipótese nula, ou seja, apesar destas variáveis não serem significativas elas devem permanecer no modelo estimado.

$\mathrm{O}$ último teste realizado identifica se as variáveis associadas à qualificação, $\mathrm{z}_{10 \mathrm{t}}, \mathrm{z}_{11 \mathrm{t}} \mathrm{e} \mathrm{z}_{18 \mathrm{t}}$, devem ser deixadas de fora do modelo estimado para a ineficiência técnica, dado que elas não são significativas nem a $10 \%$. O valor encontrado para $\Lambda, 45,45$, indica que, mesmo estas variáveis não sendo significativas, elas devem permanecer no modelo estimado. Ou seja, as variáveis associadas à qualificação influenciam no índice de ineficiência técnica apresentado pelo setor de bens de capital. 


\section{APÊNDICE A2 - DISCRIMINAÇÃO DAS ATIVIDADES QUE COMPÕE OS SETORES CONSIDERADOS}

\begin{tabular}{|c|c|c|c|c|}
\hline Indústria e agropecuária & Outras & Custo & Valor & $\begin{array}{l}\text { Telecomu } \\
\text { nicação }\end{array}$ \\
\hline Agricultura, Caça, Floresta e Pesca & $\begin{array}{l}\text { Administração Pública e } \\
\text { Defesa; Segurança Social } \\
\text { Obrigatória }\end{array}$ & Electricidade, Gás e Abastecimento de Água & $\begin{array}{l}\text { Intermediação } \\
\text { financeira }\end{array}$ & $\begin{array}{l}\text { Correios e } \\
\text { Telecomun } \\
\text { icação }\end{array}$ \\
\hline Extrativa Mineral & Educação & Construção & $\begin{array}{l}\text { Locação de } \\
\text { Máquinas e }\end{array}$ & \\
\hline Alimentos, Bebidas e Tabaco & Saúde e trabalho social & $\begin{array}{l}\text { Venda, manutenção e reparação de veículos } \\
\text { automóveis e motociclos; Venda a retalho de } \\
\text { combustível }\end{array}$ & $\begin{array}{l}\text { equipamentos e } \\
\text { Outras Atividades } \\
\text { de Negócios }\end{array}$ & \\
\hline Têxteis e produtos têxteis & Outros serviços & $\begin{array}{l}\text { Comércio por grosso e agentes do comércio, } \\
\text { excepto de veículos automóveis e motociclos }\end{array}$ & & \\
\hline Couro, couro e calçados & comunitários, sociais & $\begin{array}{l}\text { Comércio a retalho, excepto de veículos } \\
\text { automóveis e motociclos; Reparação de bens de } \\
\text { consumo }\end{array}$ & & \\
\hline Madeira e produtos de madeira e cortiça & e pessoais & Hotéis e Restaurantes & & \\
\hline Celulose, Papel, Papel, Impressão e Publicação & Famílias privadas & Transportes Terrestres & & \\
\hline Coque, Petrolei refinado e combustível nuclear & com empregados & Transporte de água & & \\
\hline Químicos e produtos químicos & Hotéis e restaurantes & Transporte aéreo & & \\
\hline Borracha e plásticos & Atividades imobiliárias & & & \\
\hline \multicolumn{5}{|l|}{ Outros minerais não-metálicos } \\
\hline \multicolumn{5}{|l|}{ Metais básicos e metais fabricados } \\
\hline \multicolumn{5}{|l|}{ Máquinas, NEC } \\
\hline \multicolumn{5}{|l|}{ Equipamentos óticos e elétricos } \\
\hline \multicolumn{5}{|l|}{ Equipamentos de transporte } \\
\hline Manufatura e reciclagem & & & & \\
\hline
\end{tabular}

